\title{
Instructor-Student Interpersonal Interaction and Student Outcomes at the University Level in Indonesia
}

\author{
Barry J. Fraser", Jill M. Aldridge and Widia Soerjaningsih \\ Key Centre for School Science and Mathematics, G.P.O. Box U1987, Curtin University of Technology, Australia
}

\begin{abstract}
This article reports the validity of the Questionnaire on Teacher Interaction (QTI), (developed to assess studentteacher interpersonal interaction) when modified, translated and used at the university level in Indonesia. We also investigated relationships between students' outcomes (achievement and attitudes) and the quality of teacher-student interactions among 422 students in 12 classes in a private university in Indonesia. Data analyses supported the QTI's validity, revealed differences between a computer science and a management department in terms of instructor-student interactions, and identified which types of instructor-student interactions are most likely to promote student outcomes at the university level.
\end{abstract}

Keywords: Attitudes, achievement, educational environments, higher education, questionnaire on teacher interaction (QTI), teacher-student interaction.

\section{INTRODUCTION}

Observations of classroom developments and practices have revealed that the interpersonal behavior of teachers plays a pivotal part in directing the flow of teaching and learning in the classroom. This universal and perennial problem clearly is linked to the teacher's ability to set the tone and gain student respect and cooperation. It is essential, therefore, that teachers establish a rapport with students that will ensure smooth functioning of the teaching-learning process. The problem also highlights the importance of the communication skills of teachers and the social and emotional backup that a teacher can provide in daily classroom communication. An assertion made by many researchers about teacher effectiveness is that the creation and maintenance of a positive classroom climate is conducive for student learning [1-4] and motivation [5]. This further underscores the fruitfulness of investigating the impact of interpersonal teacher behavior on student learning. Therefore, our study of interpersonal teacher behavior contributes to the fundamental aim of making the teacherlearning process more effective and efficient.

More specifically, research into interpersonal teacher behavior is important not only for enhancing student outcomes, but also for improving teacher competency in classroom communication. It is widely reported that communication is reciprocal, so that the behaviors of the teacher and students influence each other mutually [6-8].

Past studies of interpersonal teacher behaviors have indicated that the nature of teacher-student communication is an important element of the learning environment and is strongly related to student outcomes $[6,7,9-12]$. To date, only a few studies of the learning environment have been

*Address correspondence to this author at the Key Centre for School Science and Mathematics, G.P.O. Box U1987, Curtin University of Technology, Australia; Tel: +61 89266 7896; Fax: +61 89266 2503;

E-mail: B.Fraser@curtin.edu.au undertaken at the university level for example [13-17] and only one has been carried out in Indonesia [18]. A possible obstacle to such research at the university level could be the lack of suitable instruments.

This article reports the modification, validation and use of the Questionnaire on Teacher Interaction (QTI) for assessing university-level students' perceptions of their instructor's interpersonal behavior. This study of instructorstudent interaction has the potential to create a clearer picture of the classroom contexts and patterns of instructor-student interactions that are needed at the university level to promote good academic performance and positive attitudes amongst students. Such a study has the potential to provide information that instructors can use to modify their behavior in order to cater more adequately for the needs of students.

In addition, the present study also used the QTI in investigating the nature and impact of interpersonal instructor behavior on the achievement and attitudes of university students in Indonesia. This research provided valuable information for guiding the development of strategies for improving classroom practices and management for university-level computer-related courses.

The aims of the study were:

- to develop a valid and reliable instrument in the Indonesian language to assess instructor-student interactions.

- to describe and compare a university computer science course and a management course in terms of instructor-student interactions.

- to investigate associations between students' perceptions of instructor-student interactions and the student outcomes of achievement and attitude.

\section{BACKGROUND}

Guided by the work of Lewin [19] and Murray [20], two independent research programs initially focused on the 
development of instruments that could be used to assess the learning environment at the secondary-school level. Herbert Walberg's Learning Environment Inventory [21] and Rudolf Moos's Classroom Environment Scale [22, 23] were the first instruments developed to assess students' perceptions of their classroom learning environment. Since this time, the influence of the learning environment on the educational process has received a great deal of attention, and there has been much progress in the conceptualization, assessment and investigation of learning environments [24-26]. Whilst different data-gathering approaches, qualitative and quantitative, have been used in conducting research in the field of learning environments, the use of questionnaires to assess students' perceptions has been the predominant method.

\section{Studies of Learning Environments at the Higher Education Level}

Past work in the field of learning environments has distinguished between the classroom-level and school-level environment. School-level research at the higher education level owes much to earlier work on organizational climate in business organizations and to instruments such as the College Characteristics Index (CCI) [27]. Dorman [28, 29] developed the University-Level Environment Questionnaire (ULEQ) to assess instructors' perceptions of the Australian university environment and validated it with a sample of 489 academics from 52 departments in 28 Australian universities.

At the classroom level, Fraser and Treagust [14] developed and used the seven-scale College and University Classroom Environment Inventory (CUCEI) to assess higher education students' perceptions of aspects of the learning environment. Using a sample of 127 university students, they reported that student satisfaction was greater in classes where students perceive higher levels of involvement, task orientation and innovation. In more recent studies, the CUCEI has been used to investigate the learning environment of second-year chemical technology classes at a tertiary institution [30], to monitor the transition from senior secondary schools to the university level [31,32], and to provide feedback information to guide the improvement of nursing education learning environments [33].

Coll and Fisher [30] administered an actual and preferred version of the CUCEI to second-year chemical technology classes in the chemistry department of a tertiary institution in New Zealand. The actual version was used to assess students' perceptions of the prevailing learning environment and the preferred version was used to assess the learning environment that students would prefer. They found that, for all scales, students would prefer more of each learning environment dimension than they presently perceive. As a result of the study, Coll and Fisher recommended that learning environment instruments would make a useful addition to existing course-evaluation instruments.

Nair and Fisher [31, 32] investigated the classroom environment of 504 science classes in Australian and Canadian tertiary institutions using a modified and personalized form of the College and University Classroom Environment Inventory (CUCEI). They reported that students at the tertiary level would prefer a more favorable learning environment in all areas measured by the seven scales of the CUCEI.

More recently, Logan, Crump and Rennie [34] used a modified form of the CUCEI at the university level in two separate studies. In both studies, when the reliability and validity were found to be lower than expected, negativelyworded items and a whole scale were omitted to achieve a satisfactory factor structure.

Since the development of the CUCEI, a number of learning environment studies have been undertaken at the higher education level, including the development of instruments to assess students' perceptions of the learning environments in particular fields. In the field of medicine, the Medical Educational Environment Measure (MEEM) [35] was developed for use in a Thai nursing school and the Teaching and Learning Environment Questionnaire (TLEQ) [36] was developed for use with American university medical students. To examine university students' perceptions of their computer laboratories, Newby and Fisher [37] adapted the Science Laboratory Environment Inventory (SLEI). In a study of mathematics courses at five universities in Australia, a learning environment instrument was developed, based on factors implicated in decision making about pursuing mathematics at the university level, and validated using a sample of 1883 students attending university mathematics courses $[38,39]$. Spreda and Donnay [40] validated a single learning environment scale that was embedded in the Strong Interest Inventory developed for use in career counseling. When the questionnaire was administered to 115 first-year Midwestern American university students enrolled in a career development course, there were associations between the learning environment scale and students' career interests.

Wierstra, Kanselaar, Vander Linden and Lodewijks [41] developed a learning environment instrument to compare the perceptions of Dutch students with those of students from other European countries. The Inventory of Perceived Study Environment (IPSE) draws on scales from a range of existing instruments, including the College and University Classroom Environment Inventory (CUCEI), Classroom Environment Scale (CES) and the Individualised Classroom Environment Questionnaire (ICEQ). The IPSE was administered to 610 Dutch students and 241 foreign students.

Lizzio, Wilson and Simmons [42] investigated relationships between students' perceptions of their academic environment, their approaches to study, and their academic outcomes at the university and faculty levels. A questionnaire was administered to a large, cross-disciplinary sample of undergraduate students. When data were analysed using higher-order path and regression analyses, students' perceptions of the learning environment were found to influence both academic achievement and student satisfaction.

\section{Investigating Teacher Interpersonal Behavior}

Teacher behavior is an important component of the learning environment $[24,25,43,44]$. Research on teacher behavior and student learning has taken many forms, including a focus on teacher expectation studies $[45,46]$, the influence of teacher non-verbal behavior on student performance [47], managing classrooms and students [48], 
the influence of teacher socialization style on student cognition [49] and studies of expert and novice teachers [50]. However, it was from research that originated in The Netherlands that the study of interpersonal teacher behavior came to focus more specifically on the impact on students' learning of the interactional and mutually-influencing relationship between teacher and students. This potentiallypowerful determinant of student learning provided a catalyst for a series of research studies in teacher education since the early 1980s at the University of Utrecht, The Netherlands. Research on associations between student outcomes and interpersonal teacher behavior produced encouraging results [51-54]. Interpersonal teacher behavior has been investigated widely at the secondary school level in a number of countries $[10,54,55]$, but little research has taken place at the higher education level [17].

\section{METHOD}

The sample consisted of 422 students from 12 research methods classes in a large private university in Jakarta, Indonesia. The classes were selected from two departments within the university, Computer Science and Management. These two departments were selected because they were quite different in terms of the types of students that they attracted. Generally speaking, students enrolled in the computer science department had a good academic background and were motivated to learn. In contrast, students enrolled in the management department tended to have poorer academic performance and were typically less motivated. It was generally agreed amongst the students that management studies were easier than many of the other subjects.

In our study, we used the Questionnaire on Teacher Interaction (QTI), as well as an attitude scale. The instruments were translated into Indonesian using a rigorous process of back-translation (which involved the translation of the English version into Indonesian and the backtranslation, by an independent party, into English - allowing the comparison of the two versions) to ensure that each item retained its original meaning [56].

There has been a number of learning environment studies that have investigated student attitudes towards their class as an outcome measure. However, the majority of these studies focused specifically on science-related attitudes and none were available in the Indonesian language. The studies that focused on science related attitudes reported positive associations between students' attitudes towards science and classroom environments [24].

The present study investigated students' attitudes towards computers in higher-education classes in Indonesia. A review of the existing techniques and instruments used to measure students' attitudes to computers revealed that none of the existing instruments were available in the Indonesian language. As the students included in the study were familiar with the semantic differential technique, developed by Osgood, Suci and Tannenbaum [57, 58], we constructed our own attitude instrument based on this technique. The semantic differential technique is a direct method in that it asks respondents about their attitudes towards a certain object. In this case, the sentence "Using the internet to search for information is:" was followed by seven pairs of polarized adjectives for differentiation. The adjectives were selected from Osgood, Suci and Tannenbaum [57], with each pair of adjectives being used in conjunction with a five-point scale. The respondent circled the point on the scale which best reflected his or her feeling towards each concept or stimulus. The order for alternative pairs of the adjectives was reversed (and hence also the direction of scoring) so that respondents would not be affected by the 'underlying structure' (adjectives belonging to the same 'favorable or unfavorable ends of the scale'). The seven pairs of adjectives were:

$\begin{array}{ccc}\text { Clear } & 12345 & \text { Confusing } \\ \text { Meaningless } & 12345 & \text { Meaningful } \\ \text { Important } & 12345 & \text { Unimportant } \\ \text { Useless } & 12345 & \text { Useful } \\ \text { Easy } & 12345 & \text { Difficult } \\ \text { Boring } & 12345 & \text { Interesting } \\ \text { Pleasant } & 12345 & \text { Unpleasant }\end{array}$

Our research involved assessing students' perceptions of their teacher's interpersonal behavior using the Questionnaire on Teacher Interaction (QTI). The present study is distinctive because it extended the use for the QTI from secondary to higher education classrooms, and validated an eight-factor structure for the QTI that is in keeping with the original eight-sector model. In addition, our study investigated the nature and impact of interpersonal instructor behavior on student outcomes. On the Indonesian scene, this research has the distinction of being the first study of instructor-student interactions undertaken in highereducation classrooms.

Because there is much literature related to the development of the QTI [44], this article provides only a summary. The QTI originated in The Netherlands and was used to gather students' and teachers' perceptions of interpersonal teacher behavior. It was developed by a team of Dutch educational researchers at the University of Utrecht for their research in secondary classrooms $[8,44,53,54,59$ 61].

In response to the need for a framework for conceptualizing and measuring teacher-student interaction, Wubbels, Creton and Hooymayers [62] were inspired by the Leary model of interpersonal behavior [63], which provides a graphical representation for human interaction [64]. In adapting of the Leary model, the behaviors of teachers also were plotted along two axes: an Influence dimension (Dominance - Submission, DS) and a Proximity dimension (Cooperation - Opposition, CO), as shown in Fig. (1). According to Wubbels, Creton, Levy and Hooymayers [64], the Influence dimension portrays who is controlling or directing the communication process and how often; and the Proximity dimension indicates the degree of cooperation or closeness in the process of communication. Both dimensions are independent and reminiscent of effective teacher behaviors that could influence classroom processes. For instance, directivity and warmth are two aspects of effective teacher behavior [65], which bear a strong resemblance to Influence and Proximity. Each of these axes (DS and CO) represent opposite behaviors and constitute the axes in a coordinate system of eight sectors circumrotating the eight 
different facets of teacher behavior, namely, Leadership, Helping/Friendly, Understanding, Student Responsibility/ Freedom, Uncertain, Dissatisfied, Admonishing and Strict behavior (see Fig. 1). These eight sectors are labeled DC, $\mathrm{CD}, \mathrm{CS}, \mathrm{SC}, \mathrm{SO}, \mathrm{OS}, \mathrm{OD}$ and DO in accordance with their circular placing in the model of interpersonal teacher behavior.

This model of interpersonal teacher behavior takes the form of an octagonal circumplex, within which each of the eight sectors represents a facet of teacher behavior [66, 67]. Every instance of teacher behavior can be placed within these eight sectors [64]. As an illustration of the mapping of teacher behavior, the sectors $\mathrm{DC}$ and $\mathrm{CD}$ both include Dominance and Cooperation. In the DC sector, teacher Dominance is a stronger trait than teacher Cooperation (for example, demonstrated through the teacher holding student attention by explaining a concept to the class, setting an assignment or establishing procedures). In the $\mathrm{CD}$ sector, it is the reverse, with more teacher Cooperation and less teacher Dominance (for example, the teacher might be seen moving among groups of students assisting and motivating them in their learning).

Wubbels [68] provided a description of typical teacher behaviors belonging to each of the eight sectors, as shown in Fig. (1). For example, in the Leadership (DC) sector, teachers notice what's happening, lead, organize and give orders while, in the Strict (DO) sector, teachers keep the reins tight, get the class silent, maintain silence, exact norms and set rules. It also can be noted that these two sectors of Leadership (DC) and Strict (DO) are adjacent to each other in the model and that the types of teacher behavior encompassed by these two adjacent sectors tend to resemble each other more closely. This characteristic of adjacent scales in the model is seen in Fig. (1). For example, whereas teachers give orders, determine procedures and structure the classroom situation in the DC scale, teachers exact norms and set rules in the DO scale. Similarly, for the adjacent scales of Leadership (DC) and Helping/Friendly (CD), teachers notice what's happening, lead and hold attention. Based on the above assumption regarding adjacent scales in the model, the closer the scales are, the more the types of teacher behavior in those scales would resemble each other [64]. In other words, scores on adjacent scales, such as Strict, Leadership and Helpful/Friendly, should correlate highest with one another.

On the other hand, as a scale position in the model is located further away from another scale, it becomes increasingly more different until they are diametrically opposite to each other as in the case of Leadership and Uncertain scales. Evidently, the Leadership scale measures teacher interaction patterns (like lead, organize and give orders), which are the opposite to those measured by the Uncertain scale (for example, apologize, wait and see how the wind blows, and admit that one is in the wrong).

According to Wubbels, Creton and Hooymayers [8, 44], the Leary model not only presents researchers with a model for mapping and describing interpersonal teacher behavior, but also it provides the basis of a method for measuring such aspects of teacher behaviors. In addition, the Leary model provides an empirical explanation for the inter-relatedness of the kinds of interpersonal behavior mapped in the QTI discussed earlier in this section.

A description of each of the eight teacher behavior scale in the QTI is provided in Fig. (1). In the earlier Dutch version of the QTI, each scale of teacher behavior consisted of roughly 10 items, making a total of 77 items, based on a five-point rating scale with responses varying from Always to Never [62]. In 1991, an American version of the QTI was developed, comprising a total of 64 items, with eight items for each of the eight scales based on the same response format [69]. The QTI was translated from Dutch into English and used in the USA in a validation study [69]. This American study established the reliability and the structural validity of the translated Dutch version of the QTI in an American setting, and also compared the interpersonal teacher behaviors of Dutch and American secondary teachers. The Dutch and English versions of the QTI displayed similar internal structure and validity.

A short version was then developed, in English, for use at the secondary-school level [68]. This short form of the QTI contains a total of 48 items, with six items for each of the eight scales of teacher behavior. "This teacher talks enthusiastically about his/her subject" and "This teacher is willing to explain things again" are examples of typical items in the Leadership and Understanding teacher behavior scales, respectively. The short form was designed especially for use by teachers to obtain feedback from their students concerning teachers' interpersonal relationships with students in their classes.

With the emergence of an English version of the QTI, studies into associations between student outcomes and interpersonal teacher behavior in various countries emerged. In terms of cognitive outcomes, research has indicated that students are likely to perform better when they perceive more teacher influence [70] and more leadership, helpful/friendly and understanding behaviors [10]. According to Wubbels and Brekelmans [7], studies investigating associations between student affective outcomes and teacher interpersonal behavior display more consistent patterns than those investigating cognitive outcomes. Strong and positive relationships with student outcomes have been found with leadership and helpful/friendly behaviors, while negative relationships have been found with admonishing, dissatisfied and strict behaviors [10].

The findings from an Australian study of secondary science and mathematics classes [68] suggest that interpersonal teacher behavior is an important aspect of the learning environment as it is related to student cognitive and affective outcomes. Teachers who exhibited more Leadership, Friendly and Understanding behaviors in their interactions with students were found to foster greater student achievement, while teachers who showed more Uncertain, Dissatisfied and Admonishing behaviors produced the reverse effect.

Associations between interpersonal teacher behavior and student outcomes were explored further using both the QTI and the Science Laboratory Environment Inventory in an interesting study of student perceptions of science laboratory classroom environment, interpersonal teacher behavior and 


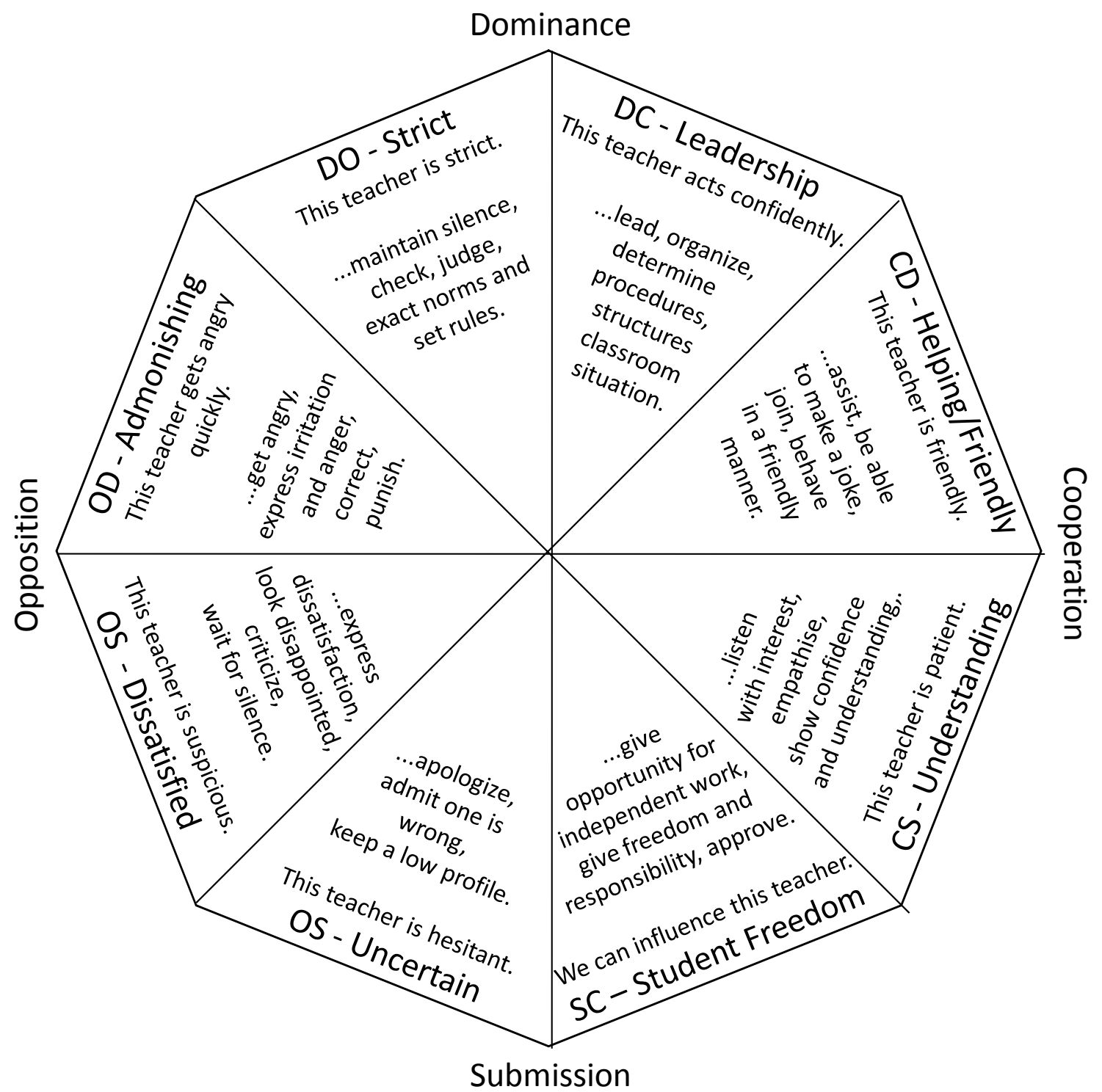

Fig. (1). Model of interpersonal teacher behavior.

student outcomes. The study, conducted in secondary biology classes in Australia, confirmed the reliability and validity of the QTI and indicated that the QTI made an appreciable contribution to the variance in student outcomes [12]. Another Australian study used perceptions of teachers and students in investigating the relationship between interpersonal teacher behavior and teacher personality in secondary classroom [67].

This area of classroom environment research involving the QTI has focused mainly on secondary science and mathematics classes in the Netherlands, USA and Australia. In more recent years, as indicated by the review above, studies involving the field of learning environments has been conducted in non-Western countries including Turkey [71], Israel [17], Kashmir [72], Singapore [73, 74], Korea [75, 76] and Brunei $[77,78]$. All of these studies supported the crossnational validity of the QTI, but none of these included the study of teacher interpersonal behavior at the university level. Therefore, it was considered timely to extend the area of study from secondary to higher education classrooms in Indonesia.
A literature review indicates that few studies worldwide have explored interpersonal relationships at the university level. One such study, Kremer-Hayon and Wubbels [17] investigated the use of the QTI in the context of teacher education in Israel. These researchers explored relationships between interpersonal relations and student teachers' satisfaction with their supervision during teaching practice in schools. This university-level version of the QTI was called the Questionnaire on Supervisor Interaction (QSI) and was considered to have satisfactory reliability and validity for assessing the interpersonal style and communication between the cooperating teachers and the student teachers.

Our study is distinctive because it extended the use for the QTI from secondary to higher education classrooms, and validated an eight-factor structure for the QTI that is in keeping with the original eight-sector model. In addition, we investigated the nature and impact of interpersonal instructor behavior on student outcomes. On the Indonesian scene, our research has the distinction of being the first study of instructor-student interactions undertaken in highereducation classrooms. 
To improve the economy of the QTI (in terms of the amount of time taken to complete the questionnaire), the number of items was reduced from eight to five items in each of the eight scales. The omission of the items was based on the relevance to the culture and circumstances at the university and involved input from the university's lecturers. Comprehensive field-testing of the QTI and attitude scales was carried out. In the first instance, the questionnaires were responded to by six staff members of Bina Nusantara University (a large private university). The researchers then sought expert opinions from staff members regarding the accuracy, clarity and general comprehensibility of items in the instruments. The interviews provided an important source of feedback information that contributed in an important way to the fine-tuning of the instruments for the main study. Once interviews with staff were complete, and modifications were made to scales on the basis of these interviews, the instruments were then field tested with 40 university students. Frequency and reliability statistics (Cronbach alpha coefficient) were used to determine which items were problematic. Interviews with students were then conducted regarding the problematic items, such as those with ambiguities, as a basis for further modifications to the questionnaires to ensure that they were clear. The pilot study provided an opportunity to simulate the main study on a reduced scale in order to evaluate (1) the comprehensibility of the items in the instruments, (2) the response format of the questionnaire, (3) the procedures for questionnaire administration, and (4) the approximate amount of time required by students to complete each of the instruments.

Finally, students' achievement was assessed using endof-year results extracted from the university data-base. All students in each course were required to take a compulsory research methods unit whose grades, based on examinations, were downloaded for use in the research with the assistance of technical staff.

Altogether there were three stages in the statistical analysis of the data from the various instruments. First, to determine the validity and reliability of the questionnaires, factor and item analyses (internal consistency reliability) and one-way ANOVA (to check each scale's ability to differentiate between classrooms, which each had a different teacher) were undertaken. Second, multivariate analysis of variance (MANOVA) was performed to investigate differences between a computer science and a management department in terms of instructor-student interactions. Third, a series of simple and multiple correlation analyses was conducted separately for each outcome to determine associations between instructor-student interactional behavior and student outcomes (course achievement and student attitudes towards computers).

\section{RESULTS}

The major finding of the present study are organized below into three sections: validation of the Questionnaire on Teacher Interaction (QTI) and attitude scale; comparing students enrolled in computer science and management courses; and associations between student outcomes and instructor-student interactions.
Validation of Questionnaire on Teacher Interaction (QTI) and Attitude Scale

The present study involved modifying, translating and validating the QTI for assessing instructor-student interactions at the university level. The new Indonesian version of the QTI (adapted from Wubbels, Brekelmans \& Hooymayers [61]) encompasses the same eight scales as the original 48-item version, namely, Leadership, Helpful/ Friendly, Understanding, Student Responsibility/Freedom, Uncertain, Dissatisfied, Admonishing and Strict behavior, However, the number of items in the Indonesian version was reduced from six to five items per scale, making a total of 40 items altogether. Also, our study includes a scale for assessing students' attitudes towards the internet.

\section{Factor Analysis for QTI}

Principal components factor analysis followed by varimax rotation resulted in the acceptance of this Indonesian version of the QTI comprising 40 items in eight scales with five items each. For the final Indonesian version of the questionnaire, nearly all items had a factor loading of at least 0.40 on their own scale and no other scale.

Table 1 shows the factor loadings for the QTI for the sample for 422 students, along with the eigenvalue and percentage of variance for each scale. For three of the eight instructor-student interaction scales, namely, Admonishing, Student Responsibility/Freedom and Strict scales, the $a$ priori factor structure was replicated perfectly. For the Dissatisfied, Leadership, Understanding and Uncertain scales, there were one or two items in each scale that loaded at least 0.40 on another scale in addition to their own scale. Modest overlap between scales is to be expected given the two-dimensional circumplex model on which the QTI is based (Fig. 1). The Helpful/Friendly scale has an item with a loading of less than 0.40 with its own scale (namely, Item 32). Therefore, Item 32 was deleted for the purposes of all subsequent data analyses reported in this article.

\section{Pattern of QTI Scale Intercorrelations}

Data regarding the validity of the QTI were also obtained from the scale intercorrelation matrix shown in Table 2. As discussed previously, the model of interpersonal teacher behavior (derived from Leary [63]) has eight scales of teacher behavior, namely, Leadership, Helpful/Friendly, Understanding, Student Responsibility/Freedom, Uncertain, Dissatisfied, Admonishing, and Strict behavior, circumrotating in a clockwise direction on the two axes of Influence and Proximity. According to this model, adjacent behavior scales (e.g., Helpful/Friendly and Understanding) should correlate highest and positively with each other, and the magnitude of the correlation should diminish as the scales become increasingly different as they move further apart from each other until they are diametrically opposite to each other, such as Helpful/Friendly and Dissatisfied, and these should have the highest negative correlation [64].

Scale intercorrelations for the QTI (shown in Table 2) generally appear to satisfy this assumption, with minor discrepancies. The Admonishing sector best illustrates this assumption in practice (see Fig. 2). The adjacent scales of 
Table 1. Factor Loading for Items of the QTI

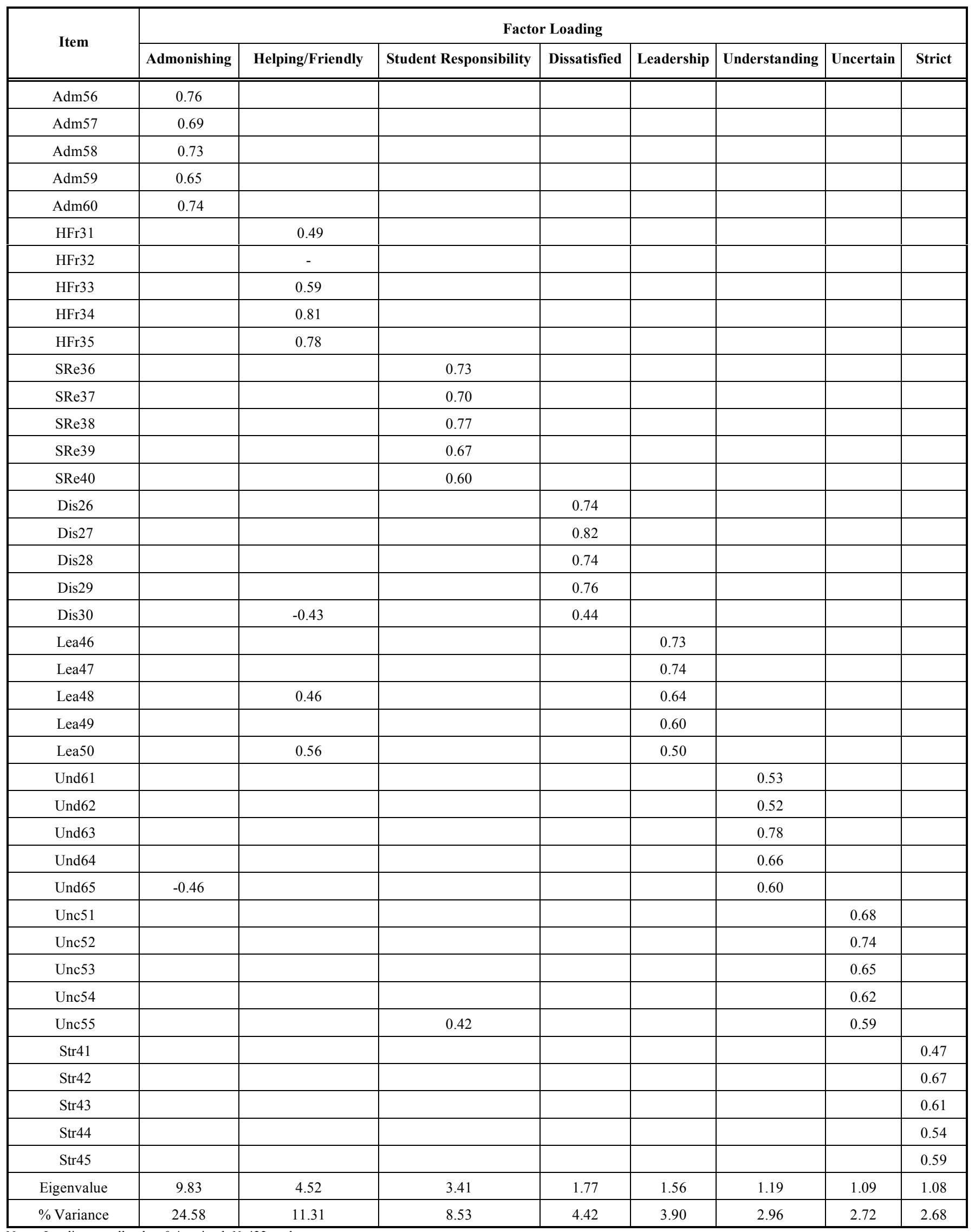


Table 2. Scale Intercorrelations for QTI

\begin{tabular}{|c|c|c|c|c|c|c|c|}
\hline \multirow{2}{*}{ QTI Scale } & \multicolumn{7}{|c|}{ Scale Intercorrelation } \\
\hline & Helping/Friendly & Understanding & Student Responsibility/Freedom & Uncertain & Dissatisfied & Admonishing & Strict \\
\hline Leadership & 0.60 & 0.49 & -0.25 & -0.42 & -0.26 & -0.04 & 0.34 \\
\hline $\begin{array}{l}\text { Helping/ } \\
\text { Friendly }\end{array}$ & - & 0.51 & -0.17 & -0.33 & -0.41 & -0.34 & 0.17 \\
\hline Understanding & & - & -0.06 & -0.40 & -0.62 & -0.83 & 0.18 \\
\hline $\begin{array}{l}\text { Student Resp./ } \\
\text { Freedom }\end{array}$ & & & - & 0.69 & 0.35 & -0.31 & -0.21 \\
\hline Uncertain & & & & - & 0.75 & 0.20 & -0.11 \\
\hline Dissatisfied & & & & & - & 0.68 & 0.12 \\
\hline Admonishing & & & & & & - & 0.25 \\
\hline
\end{tabular}

Admonishing and Strict $(r=0.62)$ and Admonishing and Dissatisfied $(r=0.68)$ correlate highest and positively. This correlation becomes smaller for scales located further from each other, and the directly opposite scale of Understanding has the highest negative correlation of -0.83 with the Admonishing scale. Fig. (2) illustrates the characteristic assumptions of the model of interpersonal teacher behavior using the Admonishing scale's correlations with its adjacent and opposite scales.

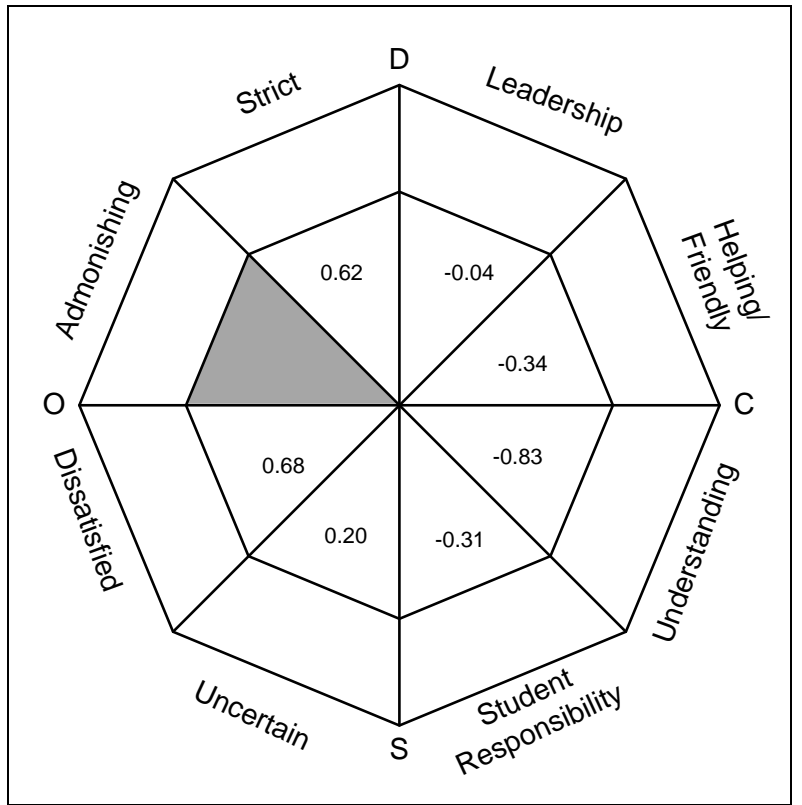

Fig. (2). Profile of scale intercorrelations for admonishing scale.

\section{QTI's Reliability and Ability to Differentiate Between Classrooms}

The Cronbach alpha coefficient was computed for each QTI scale as a measure of internal consistency. Table 3 reports the reliability of each of the eight scales of the QTI for two units of analysis: the individual student score $(N=422)$ and the class mean score $(N=12)$. The data in Table 3 suggest that the QTI has satisfactory reliability, with scale coefficients ranging from 0.65 to 0.87 with the individual as the unit of analysis and between 0.83 and 0.99 using the class mean as the unit of analysis. As anticipated, reliability estimates were higher with the class mean as the unit of analysis.

Table 3. Internal Consistency Reliability (Cronbach Alpha Coefficient) for Two Units of Analysis and Ability to Differentiate between Classrooms (ANOVA Results) for the QTI

\begin{tabular}{|c|c|c|c|}
\hline \multirow{2}{*}{ QTI Scale } & \multicolumn{2}{|c|}{ Alpha Reliability } & \multirow{2}{*}{$\frac{\text { ANOVA }}{\text { Eta }^{2}}$} \\
\hline & Individual & Class Mean & \\
\hline Leadership & 0.83 & 0.97 & $0.17 * *$ \\
\hline Helping/Friendly & 0.78 & 0.83 & $0.18^{* *}$ \\
\hline Understanding & 0.77 & 0.98 & $0.11 * *$ \\
\hline Student Responsibility & 0.80 & 0.99 & $0.08^{*}$ \\
\hline Uncertain & 0.83 & 0.99 & $0.09 * *$ \\
\hline Dissatisfied & 0.87 & 0.99 & $0.07 * *$ \\
\hline Admonishing & 0.85 & 0.98 & $0.12 * *$ \\
\hline Strict & 0.65 & 0.99 & $0.11 * *$ \\
\hline
\end{tabular}

In past research on classroom learning environments and teacher-student interpersonal interaction [25, 44], an important and commonly-used indicator of validity is the ability of questionnaire scales to be capable of differentiating between the perceptions of students in different classrooms. Because different teachers exhibit different interpersonal behaviors, it is important that the questionnaire is sufficiently sensitive to be able to distinguish between the perceptions of students who are in classes with different teachers. As each class in the present study had a different instructor, it was desirable to determine whether the QTI was able to differentiate between the 12 classes. Table 3 reports the results of an ANOVA for each QTI scale, with class membership as the independent variable. The results suggest that all scales differentiated significantly between Indonesian university classes $(p<0.05)$. Thus, students within the same class perceived instructor-student interaction in a relatively similar manner, while within-class mean perceptions of the 
students vary between classes. The eta ${ }^{2}$ statistic (calculated to provide an estimate of the strength of association between class membership and the dependent variable) ranged from 0.07 to 0.18 for different scales (see Table 3 ).

The foregoing discussion suggests satisfactory validity for the Indonesian version of the QTI based on its factor structure, pattern of scale intercorrelations, internal consistency reliability, and ability to differentiate between the perceptions of students in different classes. The results of this study of university-level students in Indonesia compare favorably with those for secondary students in The Netherlands, the USA and Australia [68], Turkey [71], Israel [17], India [72], Singapore [73, 74], Korea [75, 76] and Brunei [77, 78]. Therefore, instructors and researchers in Indonesia can use the QTI with confidence in the future.

\section{Reliability of Attitude Scale}

For our study, we developed an Attitude towards the Internet scale. The data collected from 422 students in 12 classes were used to examine the internal consistency reliability (Cronbach alpha coefficient) of the Attitude towards the Internet scale. The reliability estimate was 0.86 using the individual as the unit of analysis and 0.97 using the class mean as the unit of analysis.

\section{Comparing Students Enrolled in Computer Science and Management Courses}

A one-way MANOVA was performed with the eight QTI scales as dependent variables and the course (computer science or management) as the independent variable. When the multivariate test yielded significant results $(p<0.01)$ in terms of Wilks' lambda criterion for the set of criterion variables as a whole, the one-way ANOVA was interpreted for each of the eight individual QTI scales. The results of the $F$ tests are shown in Table $\mathbf{4}$ along with descriptive statistics. In order to estimate the magnitudes of between-course differences (in addition to their statistical significance), effect sizes were calculated as recommended by Thompson $[79,80]$. The effect size was calculated by dividing the difference between department means by the pooled standard deviation.

With respect to perceptions of instructor interpersonal behavior, analyses revealed that students enrolled in management courses perceived their instructors as exhibiting significantly more positive interaction qualities in terms of Leadership, Helping/Friendly and Understanding behaviors, compared with students enrolled in computer science courses. The effect sizes for those QTI scales with significant between-course differences were of reasonable size, ranging from about one-third of a standard deviation (0.35) to two-thirds of a standard deviation (0.63). The results also indicate that students enrolled in management courses consistently perceived their instructors' interpersonal behavior more favorably on all scales (i.e., higher scores on scales with a positive connotation and lower scores on scales with a negative connotation) than did Computer Science students (see Table 4).

As discussed earlier, Management courses are generally perceived by students to be easier than Computer Science

Table 4. Average Item Mean, Average Standard Deviation and Difference between Departments (Effect Size and MANOVA Results for Independent Samples) for QTI

\begin{tabular}{|c|c|c|c|c|c|}
\hline Scale & Department & Average Item Mean ${ }^{a}$ & $\frac{\text { Average Item Standard }}{\text { Deviation }}$ & \multicolumn{2}{|c|}{ Difference } \\
\hline Leadership & Management & 3.34 & 0.73 & & \\
\hline Helping/Friendly & Computer Science & 2.91 & 0.65 & -0.63 & $2.20 * *$ \\
\hline \multirow{2}{*}{ Understanding } & Computer Science & 3.42 & 0.68 & -0.35 & $1.83 * *$ \\
\hline & Management & 3.66 & 0.71 & & \\
\hline \multirow{2}{*}{ Student Responsibility } & Computer Science & 2.16 & 0.72 & 0.19 & 1.32 \\
\hline & Management & 2.03 & 0.68 & & \\
\hline Dissatisfied & Management & 2.07 & 0.85 & & \\
\hline \multirow{2}{*}{ Admonishing } & Computer Science & 1.91 & 0.74 & 0.15 & 1.22 \\
\hline & Management & 1.80 & 0.75 & & \\
\hline \multirow{2}{*}{ Strict } & Computer Science & 2.99 & 0.65 & -0.11 & 1.04 \\
\hline & Management & 3.06 & 0.64 & & \\
\hline
\end{tabular}

Note: $N=278$ students enrolled in Computer Science courses and 144 students enrolled in Management courses.

${ }^{a}$ Average item mean $=$ Scale mean divided by the number of items in that scale.

$* * p<0.01$. 
courses. Students electing to enroll in Management courses also are generally less strong academically. In addition, it would appear from these results that the students enrolled in the two courses have quite different perceptions of their lecturers' interpersonal behaviors, with students enrolled in Management courses consistently perceiving more favorable perceptions of their lecturers' interpersonal behaviors than their counterparts enrolled in Computer Science.

\section{Associations Between Student Outcomes and Instructor- Student Interaction}

There has been much research in the past that has indicated that a teacher's interpersonal behavior is strongly related to students' achievement at various grade levels and in numerous countries $[44,52,81]$. Therefore this section reports associations between perceived interpersonal instructor behavior and students' outcomes (cognitive and affective).

As noted previously, our measure of students' achievement was the grade obtained on completion of the Research Methods unit and our measure of students' attitudes was a semantic differential scale designed specifically for our study. The statistical procedures used in investigating associations between students' outcomes and interpersonal instructor behavior were simple correlation and multiple regression analysis. The standardized regression weight $(\beta)$ was computed to provide information about the unique contribution of each scale to an outcome score when all other scales were mutually controlled.

Table 5 shows the results obtained for associations between each student outcome and each QTI scale. With the individual student as unit of analysis, the results of the simple correlation analysis indicate that the Dissatisfied, Admonishing and Strict scales of the QTI were statistically significantly $(p<0.05)$ and negatively related to student course achievement scores, while the Helpful/Friendly and Understanding scales were statistically significantly $(p<0.01)$ and positively related to student course achieve-ment scores.

Table 5. Simple Correlations (r), Multiple Correlations (R) and Standardised Regression Coefficients $(\beta)$ for Associations Between QTI Scales and Two Student Outcomes

\begin{tabular}{|c|c|c|c|c|}
\hline \multirow{2}{*}{ QTI Scale } & \multicolumn{3}{|c|}{ Associations with QTI Scales } \\
\cline { 2 - 5 } & \multicolumn{2}{c|}{$\begin{array}{c}\text { Course } \\
\text { Achievement }\end{array}$} & \multicolumn{2}{c|}{$\begin{array}{c}\text { Attitude } \\
\text { Towards Internet }\end{array}$} \\
\cline { 2 - 5 } & $\boldsymbol{r}$ & $\boldsymbol{\beta}$ & $\boldsymbol{r}$ & $\boldsymbol{\beta}$ \\
\hline \hline Leadership & 0.05 & 0.00 & 0.06 & $0.17^{*}$ \\
\hline Helping/Friendly Behavior & $0.12^{* *}$ & 0.09 & 0.02 & 0.03 \\
\hline Understanding & $0.16^{* *}$ & 0.11 & -0.07 & $0.14^{*}$ \\
\hline Student Responsibility & 0.08 & 0.08 & 0.04 & 0.00 \\
\hline Uncertain & -0.04 & 0.02 & $-0.10^{*}$ & $-0.18^{* *}$ \\
\hline Dissatisfied & $-0.12^{*}$ & -0.02 & 0.03 & 0.02 \\
\hline Admonishing & $-0.18^{* *}$ & -0.09 & 0.00 & -0.11 \\
\hline Strict & $-0.16^{* *}$ & $-0.16^{* *}$ & 0.00 & 0.01 \\
\hline Multiple Correlation $(R)$ & & $0.28^{* *}$ & & $0.19^{*}$ \\
\hline Note: ${ }^{*} p<0.05 * * p<0.01$. & & & & \\
\hline
\end{tabular}

The multiple correlation $(R)$ between students' perceptions of the set of eight QTI scales and the students' course score (Table 5) was only 0.28 , but still was statistically significant $(p<0.01)$, suggesting that the set of perceived instructor-student interaction scales was related to the students' course achievement score. Table 5 indicates that only one of the eight QTI scales uniquely accounted for a significant amount of variance in course score (the Strict scale) when the other QTI scales were mutually controlled.

For Attitude towards the Internet, Table 5 indicates that only the Uncertain scale had a statistically significant (and negative) correlation. The multiple correlation $(R)$ between students' perceptions of instructor-student interaction was statistically significant for Attitudes towards Internet, with the QTI scales uniquely accounting for a significant proportion of variance being Leadership, Understanding and Uncertain behaviors.

It is noteworthy that every significant bivariate and multivariate outcome-environment association in Table $\mathbf{5}$ is in the anticipated directions. That is, associations with student outcomes were positive for those QTI scales with a positive connotation (Leadership, Helping/Friendly, and Understanding behaviors) and negative for those QTI scales with a negative connotation (Uncertain, Dissatisfied, Admonishing and Strict behaviors). It should be noted that the correlation coefficients, even though statistically significant, were relatively small in magnitude (therefore reducing the educational significance of the results).

Our findings among Indonesian university students replicate considerable past research indicating a positive link between a favorable classroom learning environment (specifically positive teacher-student interactions) and improved student achievement and attitudes [25, 43, 44, 52]. For example, Goh and Fraser [81] found improved student achievement among teachers with more leadership and understanding behavior and less uncertain behavior. The present study replicates research by Quek, Wong and Fraser [52] and Goh and Fraser [81] in that more positive attitudes seem to be generally linked with more of the behaviors that can be considered to be favorable (leadership, helpful/f riendly, understanding and student responsibility and freedom) and less of the behaviors considered less favorable (uncertain, dissatisfied, admonishing and strict).

\section{DISCUSSION}

The present study focused on perceived instructorstudent interpersonal behavior and its impact on the achievement and attitudes of students at the university level in Indonesia. The study also investigated differences between a computer science and a management department in terms of instructor-student interpersonal behavior. An important methodological contribution was the careful adaptation, translation and validation of an Indonesian version of the Questionnaire on Teacher Interaction (QTI).

Analyses of QTI data from 422 university students resulted in the acceptance of the original eight-scale factor structure. The pattern of scale intercorrelations for the QTI generally satisfied the assumption of Leary's [63] model in that there was a higher correlation between scales adjacent to each other and that the correlation became smaller for scales located further from each other. Analyses also indicated 
relatively high internal consistency reliability and supported the ability of each QTI scale to differentiate between the perceptions of students in different classrooms.

We found that students from a management department, relative to students from a computer science department, perceived their instructors as exhibiting significantly more positive interactions in terms of Leadership, Helping/ Friendly and Understanding behaviors. This is interesting given that courses in the Management department are generally considered to be less difficult than those in the computer science course.

Simple correlation and multiple regression analyses revealed positive associations between student outcomes (achievement and attitudes) and more favorable teacherstudent interactions (i.e. higher scores on the QTI scales with a positive connotation and lower scores on the QTI scales with a negative connotation). This pattern of results replicates previous research in Australia [12, 55], Singapore [73, 82], Korea [75] and Brunei [77, 78].

\section{CONCLUSIONS}

This study is important because it is one of only a handful of studies in the field of learning environments in Indonesia, and it represents one of the few studies worldwide that have focused on the learning environment at the university level. This study also is noteworthy in that, by refining, translating, field-testing, validating and using a modified version of the Questionnaire on Teacher Interaction (QTI), it has provided other researchers with a widelyapplicable, parsimonious, valid, economical, and 'nonthreatening' instrument for future use in assessing and monitoring students' perceptions of instructor-student interactions. Although the QTI has been used in studies in secondary classrooms in several countries [43] and in elementary schools in Singapore [10], this was the first time that it has been used in Indonesia.

Given that the two departments attract quite different types of students and are perceived as being quite different in terms of their learning strategies used and course content, it is interesting to note that the students also reported quite different perceptions of their lecturers' interpersonal behavior. It would be useful in future research to investigate whether students' perceptions of course difficulty are related to the interpersonal behavior. Also, research involving qualitative data would be useful for providing richer and causal explanations.

In investigating associations between student perceptions of classroom environment and their learning outcomes, the study provides some practical and tentative guidance for improving student achievement and attitudes through changing patterns of instructor-student interaction. For example, our study suggests that teachers wishing to improve academic achievement should show more leadership and understanding behaviors and less uncertain behavior in their classrooms. Our study also provides some implications for future research. The future inclusion of qualitative data is needed to help to explain patterns of associations and to determine whether students' perceptions of the interpersonal behavior of lecturers can be changed, thereby enhancing students' achievement.

\section{REFERENCES}

[1] Brophy J, Good T. Teacher behavior and student achievement. In: Wittrock MC, Ed. Handbook of Research on Teaching. 3rd ed. New York, NY: Macmillan 1986; pp. 328-75.

[2] Doyle W. Classroom organization and management. In: Wittrock MC, Ed. Handbook of Research on Teaching. 3rd ed. New York, NY: Macmillan 1986; pp. 392-43.

[3] Emmer E, Evertson C, Anderson L. Effective classroom management at the beginning of the school year. Elem Sch J 1980; 80: 219-31.

[4] Leonidas K. Drawing from teacher effectiveness research and research into teacher interpersonal behavior to establish a teacher evaluation system: a study on the use of student ratings to evaluate teacher behavior. J Classroom Interact 2005; 40: 44-66.

[5] den Brok P, Levy J, Brekelmans M, Wubbels T. The effect of teacher interpersonal behavior on students' subject-specific motivation. J Classroom Interact 2005; 40: 20-33.

[6] den Brok P, Brekelmans M, Wubbels T. Interpersonal teacher behavior and student outcomes. Sch Eff Sch Improv 2004; 15: 40722.

[7] Wubbels T, Brekelmans M. Two decades of research on teacherstudent relationships in class. Int J Educ Res 2005; 43: 6-24.

[8] Wubbels T, Creton HA, Hooymayers HP. Review of research on teacher communication styles with use of the Leary model. J Classroom Interact 1992; 27: 1-11.

[9] den Brok P. Teaching and student outcomes: a study on teachers' thoughts and actions from interpersonal and a learning activities perspective. Utrecht: W.C.C. 2001.

[10] Goh SC, Fraser BJ. Teacher interpersonal behavior, classroom environment and student outcomes in primary mathematics in Singapore. Learn Environ Res 1998; 1: 199-229.

[11] Henderson DG, Fisher DL. Interpersonal behavior and student outcomes in vocational education classes. Learn Environ Res 2008; 11: 19-29.

[12] Henderson D, Fisher DL, Fraser BJ. Interpersonal behavior, laboratory learning environments, \& student outcomes in senior biology classes. J Res Sci Teach 2000; 37: 26-43.

[13] Dorman JP. The development and validation of an instrument to assess institutional-level environments in universities. Learn Environ Res 1998; 2: 79-98.

[14] Fraser BJ, Treagust DF. Validity and use of an instrument for assessing classroom psychosocial environment in higher education. High Educ 1986; 15: 37-57.

[15] Goh SC, Tobin K. Student and teacher perspectives in computermediated learning environments in teacher education. Learn Environ Res 1999; 2: 169-90.

[16] Martin-Dunlop C, Fraser BJ. Learning environment and attitudes associated with an innovative course designed for prospective elementary teachers. Inter J Sci Math Educ 2007; 6: 163-90.

[17] Kremer-Hayon L, Wubbels T. Interpersonal relationships of cooperation teachers and student teachers' satisfaction with supervision. J Classroom Interact 1992; 27: 31-8.

[18] Margianti ES, Aldridge JM, Fraser BJ. Learning environment perceptions attitudes and achievement among private university students in Indonesia [Online]. Int J Private High Educ. Retrieved 2004 Nov 19. Avalaiable from: www.xaiu.com/xaiujournal

[19] Lewin K. Principles of Topological Psychology. New York, NY: McGraw 1936.

[20] Murray HA. Explorations in personality. New York, NY: Oxford University Press 1938.

[21] Anderson G J, Walberg HJ. Classroom climate and group learning. Inter J Educ Sci 1968; 2: 175-80.

[22] Moos RH. The social climate scales: an overview. Palo Alto, CA: Consulting Psychologists Press 1974.

[23] Moos RH, Trickett EJ. Classroom environment scale manual. 1st ed. Palo Alto, CA: Consulting Psychologist Press 1974.

[24] Fraser BJ. Science learning environments: assessment, effects and determinants. In: Fraser BJ, Tobin K, Eds. International Handbook of Science Education. Dordrecht, The Netherlands: Kluwer 1998; pp. 527-64.

[25] Fraser BJ. Classroom learning environments. In: Abell SK, Lederman NG, Eds. Handbook of Research on Science Education. Mahwah, NJ: Lawrence Erlbaum 2007; pp. 103-24.

[26] Goh SC, Khine SM, Eds. Studies in educational learning environments. Singapore: World Scientific 2002. 
[27] Stern GG. People in context: measuring person-environment congruence in education and industry. New York, NY: Wiley 1970.

[28] Dorman JP. Validation and use of an instrument to assess university-level psychosocial environment in Australian universities. J Further High Educ 2000; 24: 25-38.

[29] Dorman JP. Using academics' perceptions of university environment to distinguish between Australian universities. Educ Stud 2000; 26: 205-12.

[30] Coll R, Fisher D. Learning environment instruments and their relevance for tertiary science teachers. J Sci Math Educ Southeast Asia 2000; 23: 33-47.

[31] Nair CS, Fisher DL. Students' perceptions of tertiary science classroom environments. J Sci Math Educ Southeast Asia 2001; 24: 50-67.

[32] Nair CS, Fisher DL. Transition from senior secondary to higher education: a learning environment perspective. Res Sci Educ 2001; 30: 435-50.

[33] Fisher DL, Parkinson CA. Improving nursing education classroom environments. J Nurs Educ 1998; 37: 232-6.

[34] Logan KA, Crump BJ, Rennie LJ. Measuring the computer classroom environment: Lessons learned from using a new instrument. Learn Environ Res 2006; 9: 67-93.

[35] Pimparyon P, Roff S, McAleer S, Poonchai B, Pemba S. Educational environment, students approaches to learning and academic achievement in a Thai nursing school. Med Teach 2000; 22: 359-64.

[36] Chauvin SW, Bowdish BE. An exploratory factor analysis to establish the construct validity of the teaching and learning environment questionnaire (TLEQ): paper presented at the annual meeting of the American educational research association, San Diego 1998.

[37] Newby M, Fisher DL. An instrument for assessing the learning environment of a computer laboratory. J Educ Comput Res 1997; 16: 179-90.

[38] Forgasz HJ. The typical Australian university mathematics student: challenging myths and stereotypes? High Educ 1998; 36: 87-108.

[39] Forgasz HJ, Leder GC. Perceptions of the tertiary learning environment: is mathematics worth the effort? Inter $\mathrm{J}$ Math Educ Sci Tech 2000; 31: 37-42.

[40] Spreda SL, Donnay DAC. Validating the learning environment scale of the student interest inventory for use with first year college students: paper presented at the annual conference of the American Psychological Association. Washington, DC, August 2000.

[41] Wierstra RFA, Kanselaar G, Van der Linden JL, Lodewijks HGLC. Learning environment perceptions of European university students. Learn Environ Res 1999; 2: 79-98.

[42] Lizzio A, Wilson K, Simons R. University students' perceptions of the learning environment and academic outcomes: implications for theory and practice. Stud High Educ 2002; 27: 27-52.

[43] Fraser BJ, Walberg HJ. Research on teacher-student relationships and learning environments: Context, retrospect and prospect. Inter J Educ Res 2005; 43: 103-09.

[44] Wubbels T, Brekelmans M. Teacher student relationships in the classroom. In: Fraser BJ, McRobbie C, Tobin K, Eds. The second international handbook of science education. Dordrecht, The Netherlands: Springer 1984; (in press).

[45] Cooper HM, Tom DYH. Teacher expectation research: a review with implications for classroom instruction. Elem Sch J 1984; 85: $77-89$

[46] Good TL. Two decades of research on teacher expectations: findings and future directions. J Teach Educ 1987; XXXVIII: 3247.

[47] Woodfolk AE, Brooks DM. Beyond words: the influence of teachers' nonverbal behaviors on students' perceptions and performance. Elem Sch J 1985; 85: 513-28.

[48] Brophy J. Educating teachers about managing classrooms and students. Teach Teach Educ 1988; 4: 1-8.

[49] Rohrkemper MM. The influence of teacher socialization style on students' social cognition and reported interpersonal classroom behavior. Elem Sch J 1984; 85: 244-75.

[50] Berliner D. In pursuit of the expert pedagogue. Educ Res 1986; 15(7): 5-13.

[51] Creton HA, Wubbels T, Hooymayers HP. Escalated disorderly situations in the classroom and the improvement of these situations. Teach Teach Educ 1989; 5: 205-15.
[52] Quek CL, Wong AFL, Fraser BJ. Teacher-student interaction and gifted students' attitudes toward chemistry in laboratory classrooms in Singapore. J Classroom Inter 2005; 40: 18-25.

[53] Wubbels T, Creton HA, Holvast A. Undesirable classroom situations: A systems communication perspective. Interchange 1988; 19(2): 25-42.

[54] Wubbels T, Levy J, Eds. Do you know what you look like? interpersonal relationships in education. London: Falmer Press 1993.

[55] Fisher D, Henderson D, Fraser B. Laboratory environments and student outcomes in senior high school biology. Am Biol Teach 1997; 59(2): 14-9.

[56] Brislin RW. Translation and content analysis of oral and written material. In: Triandis H, Berry J, Eds. Handbook of cross-cultural psychology: methodology. London: Allyn \& Bacon 1980; vol. 2 : pp. 389-444.

[57] Osgood CE, Suci GJ, Tannenbaum PH. The measurement of meaning. Urbana, IL: University of Illinois Press 1957.

[58] Mueller DJ. Measuring social attitudes. New York, NY: Teacher College Press 1986.

[59] Brekelmans M, Wubbels T, Creton HA. A study of student perceptions of physics teacher behavior. J Res Sci Teach 1990; 27 335-50.

[60] Creton HA, Hermans JJ, Wubbels T. Improving interpersonal teacher behavior in the classroom: a systems communication perspective. South Pac J Teach Educ 1990; 18: 85-94.

[61] Wubbels T, Brekelmans M, Hoomayers H. Interpersonal teacher behavior in the classroom. In: Fraser BJ, Walberg HJ, Eds. Educational environments: evaluation, antecedents and consequences. Oxford, England: Pergamon Press 1991; pp. 141-60.

[62] Wubbels T, Creton HA, Hooymayers HP. Discipline problems of beginning teachers: Paper presented at the annual meeting of the American Educational Research Association, Chicago, IL, April, 1985.

[63] Leary T. An interpersonal diagnosis of personality. New York, NY: Ronald Press 1957.

[64] Wubbels T, Creton HA, Levy J, Hooymayers HP. The model for interpersonal teacher behavior. In: Wubbels T, Levy J, Eds. Do you know what you look like? interpersonal relationships in education. London: Falmer Press 1993; pp. 13-28.

[65] Dunkin MJ, Biddle BJ. The study of teaching. New York: Rinehart \& Winston 1974

[66] Becker WC, Krug RS. A circumplex model for social behavior in children. Child Dev 1964; 35: 371-396.

[67] Kent HA. Meeting student needs: teacher personality and interpersonal style in the classroom: Paper presented at the Second National Conference on Post Compulsory Education, Launceston College, Launceston, Tasmania, May 1992.

[68] Wubbels T. Teacher-student relationships in science and mathematics classes (What Research Says to the Science and Mathematics Teacher, No. 11). Perth: National Key Centre for School Science and Mathematics, Curtin University of Technology 1993

[69] Wubbels T, Levy J. A comparison of the interpersonal behavior of Dutch and American teachers. Inter J Intercult Relat 1991; 15: 1-8.

[70] Brekelmans M, Wubbels T, Levy J. Student performance, attitudes, instructional stratifies and teacher-communication style. In: Wubbels T, Levy J, Eds. Do you know what you look like? interpersonal relationships in education. London: Falmer Press 1993; pp. 56-63.

[71] Telli S, den Brok P, Cakiroglu J. Students' perceptions of science teachers' interpersonal behaviour in secondary school: development of a Turkish version of the Questionnaire on Teacher Interaction. Learn Environ Res 2007; 10: 115-29.

[72] den Brok P, Fisher DL, Koul R. The importance of teacher interpersonal behavior for secondary science students' attitudes in Kashmir. J Classroom Interact 2005; 40: 5-19.

[73] Goh SC, Fraser BJ. Teacher interpersonal behavior and elementary student outcomes. J Res Childhood Educ 2000; 14(2): 216-31.

[74] Quek CL, Wong AFL, Fraser BJ. Teacher-student interaction and gifted students' attitudes toward chemistry in laboratory classrooms in Singapore. J Classroom Interact 2005; 40(1): 18-28.

[75] Kim HB, Fisher DL, Fraser BJ. Classroom environment and teacher interpersonal behavior in secondary science classes in Korea. Eval Res Educ 2000; 14: 3-22. 
[76] Lee SSU, Fraser BJ, Fisher DL. Teacher-student interactions in Korean high school science classes. Inter J Sci Math Educ 2003; 1: 67-85.

[77] den Brok P, Fisher D, Scott R. The importance of teacher interpersonal behavior for student attitudes in Brunei primary science classes. Inter J Sci Educ 2005; 27: 765-79.

[78] Scott RW, Fisher DL. Development, validation and application of a Malay translation of an elementary version of the Questionnaire on Teacher Interaction. Res Sci Educ 2004; 34: 173-94.

[79] Thompson B. Review of 'what if there were no significance tests?' Educ Psychol Measure 1998; 58: 334-46.
[80] Thompson B. Significance, effect sizes, stepwise methods and other issues: Strong arguments move the field. J Exp Educ 2001; 7: 80-93.

[81] Goh SC, Fraser BJ. Teacher interpersonal behavior, classroom environment and outcomes in primary mathematics in Singapore. Learn Environ Res 1998; 1: 199-229.

[82] Goh SC, Young DJ, Fraser BJ. Psychosocial climate and students' outcome in elementary mathematics classrooms: a multilevel analysis. J Exp Educ 1995; 64: 29-40.

Received: August 15, 2009

Revised: January 1, 2010

Accepted: January 8, 2010

(c) Fraser et al.; Licensee Bentham Open.

This is an open access article licensed under the terms of the Creative Commons Attribution Non-Commercial License (http://creativecommons.org/licenses/by-nc/ $3.0 /$ ) which permits unrestricted, non-commercial use, distribution and reproduction in any medium, provided the work is properly cited. 